\title{
Magnifying effects on visual word recognition: A dynamic display for Internet-based experiments
}

\author{
JAN EICHSTAEDT \\ Helmut Schmidt University, Hamburg, Germany
}

\begin{abstract}
A visual presentation procedure is introduced that presents target words followed by a dynamic mask until recognition. This form of stimulus degradation prolongs the word recognition process. Differences in word recognition latencies — which are usually quite small—are magnified, and thus can be more easily observed. The results of two experiments on the Internet with a total of 141 participants establish the task's ability to magnify differences in word recognition latencies stemming from word familiarity (Experiment 1) and word prototypicality (Experiment 2). Both factors interact with stimulus degradation, but at different presentation intervals; these results are discussed as evidence for comparing models of word recognition. The new procedure can be used for assessing individual differences, such as implicit motives and self-focused attention. Further applications are discussed.
\end{abstract}

Differences in word recognition latencies due to semantic factors are mostly quite small. The small size of these differences almost precludes applications of latency-based assessment methods in the study of social cognition and individual differences. In particular, when doing Internet-based experiments, small but interesting differences might be overlooked because reaction time measurement over the Internet can be error prone (Eichstaedt, 2001). Therefore, the present article introduces a procedure of visual word recognition for magnifying the effects of cognitive processing on recognition latencies. The procedure is realized in software as a dynamic display that makes it possible to measure traits and states in social and personality psychology on the basis of word recognition latencies. Some first applications of the dynamic display include assessments of implicit motives (Eichstaedt \& Scheffer, 2005), self-focused attention (Eichstaedt \& Silvia, 2003; Silvia, Eichstaedt, \& Phillips, 2005), and the effects on word recognition latencies of content category membership, expectancy, and knowledge (Eichstaedt, 2002). These applications benefit from magnifying semantic impacts on word recognition latencies. Moreover, the dynamic display helps to reduce unwanted effects on latencies such as movement initiation time, because the technique increases only recognition times and not motor response times. The present article illustrates in two Internet-based experiments the dynamic display's utility for magnifying lexical and semantic effects previously es-

I thank Franziska Scherer and Paul Silvia for their helpful comments on an earlier draft of this article. Correspondence should be addressed to J. Eichstaedt, Department of Psychology, Helmut Schmidt University, Holstenhofweg 85, D-22039 Hamburg, Germany (e-mail: jan.eichstaedt (a)hsu-hamburg.de).

Note-This article was accepted by the previous editor, Jonathan Vaughan. tablished in cognitive psychology - that is, the effects of familiarity and prototypicality.

Familiarity and prototypicality are qualities of words, the former referring to the lexical and the latter to the semantic organization of words in memory. The prototypicality of a word as an exemplar of a given category has been investigated extensively in lexical decision tasks and pronunciation tasks (see, e.g., Keefe \& Neely, 1990; Lorch, Balota, \& Stamm, 1986; Massaro, Jones, Lipscomb, \& Scholz, 1978; Neely, Keefe, \& Ross, 1989). Prototypicality is an instance of semantic relatedness between the category name and the exemplar name. In contrast, word frequency and familiarity are lexical properties of a given word that have also been investigated extensively in lexical decision and pronunciation tasks (e.g., Becker, 1979; Connine, Mullennix, Shernoff, \& Yelen, 1990; Lewellen, Goldinger, Pisoni, \& Greene, 1993; Morrison, Ellis, \& Quinlan, 1992; Scarborough, Cortese, \& Scarborough, 1977).

Word frequency and semantic relatedness have been found to interact overadditively - that is, with a combined effect stronger than the sum of both single effects - in lexical decision (see, e.g., Becker, 1979) and to yield a lowfrequency priming advantage in word fragment completion (MacLeod \& Kampe, 1996). Likewise, stimulus degradation and semantic relatedness have also been found to interact overadditively in lexical decision (Besner \& Smith, 1992; Stolz \& Neely, 1995; see Neely, 1991, for a review). To date, however, there has been almost no evidence for an interaction between word frequency and stimulus degradation (but see Norris, 1984; Wilding, 1988). According to the additive-factors logic (Sternberg, 1969), the sole interaction of a semantic rather than a lexical factor with stimulus degradation is challenging evidence for sequential models of word recognition (e.g., Becker, 1980; Morton, 1969), because such an interaction undermines the view of word recognition as a sequence of 
first visually recognizing the graphical parts of a word, then matching the word with the content of lexical memory, and finally retrieving the word's semantics. If lexical information, such as word frequency, takes effect before semantic relatedness, then word frequency should also interact with stimulus degradation - which has not been found. However, semantic priming effects are quite small $(7-166 \mathrm{msec})$ when investigated using either the lexical decision or the pronunciation task (Neely, 1991). At such a small scale, the interaction effects of word frequency with stimulus degradation might simply be overlooked. The dynamic display allows a closer look at both interactions, because it magnifies top-down effects from milliseconds to seconds. ${ }^{1}$

\section{How the Dynamic Display Works}

There is reliable evidence that semantic effects on word recognition latencies are stronger when target words are degraded (Becker \& Killion, 1977; Besner \& Smith, 1992; Borowsky \& Besner, 1991, 1993, 2000; Massaro et al., 1978; Meyer, Schvaneveldt, \& Ruddy, 1975; Stolz $\&$ Neely, 1995). Magnifying latency differences with the dynamic display relies on this effect. With the dynamic display, participants look for words under difficult perceptual conditions and are asked to indicate as quickly and as accurately as possible when they recognize a word.

In the two experiments reported here, three lines of flickering random letters were displayed using the monospace computer font Courier, in which all letters are equal in width. The apparent flickering consisted of repeated tachistoscopic presentations of random letters, using a new set of random letters for each presentation. Within the random letters of the center line, a target word was spatially and temporally embedded. Spatially, the target word was placed within random letters filling the letter positions from the beginning of the line to the start of the word and from the end of the word to the end of the line. The target word was also temporally embedded, which made the display dynamic. That is, between two tachistoscopic presentations of random letter strings, the target word was presented (within the random letters), also tachistoscopically, replacing the random letters of the previous presentation and being replaced by other random letters in the next presentation (see Figure 1). Thus, the target word was immediately masked after its presentation; that is, the target presentation was followed

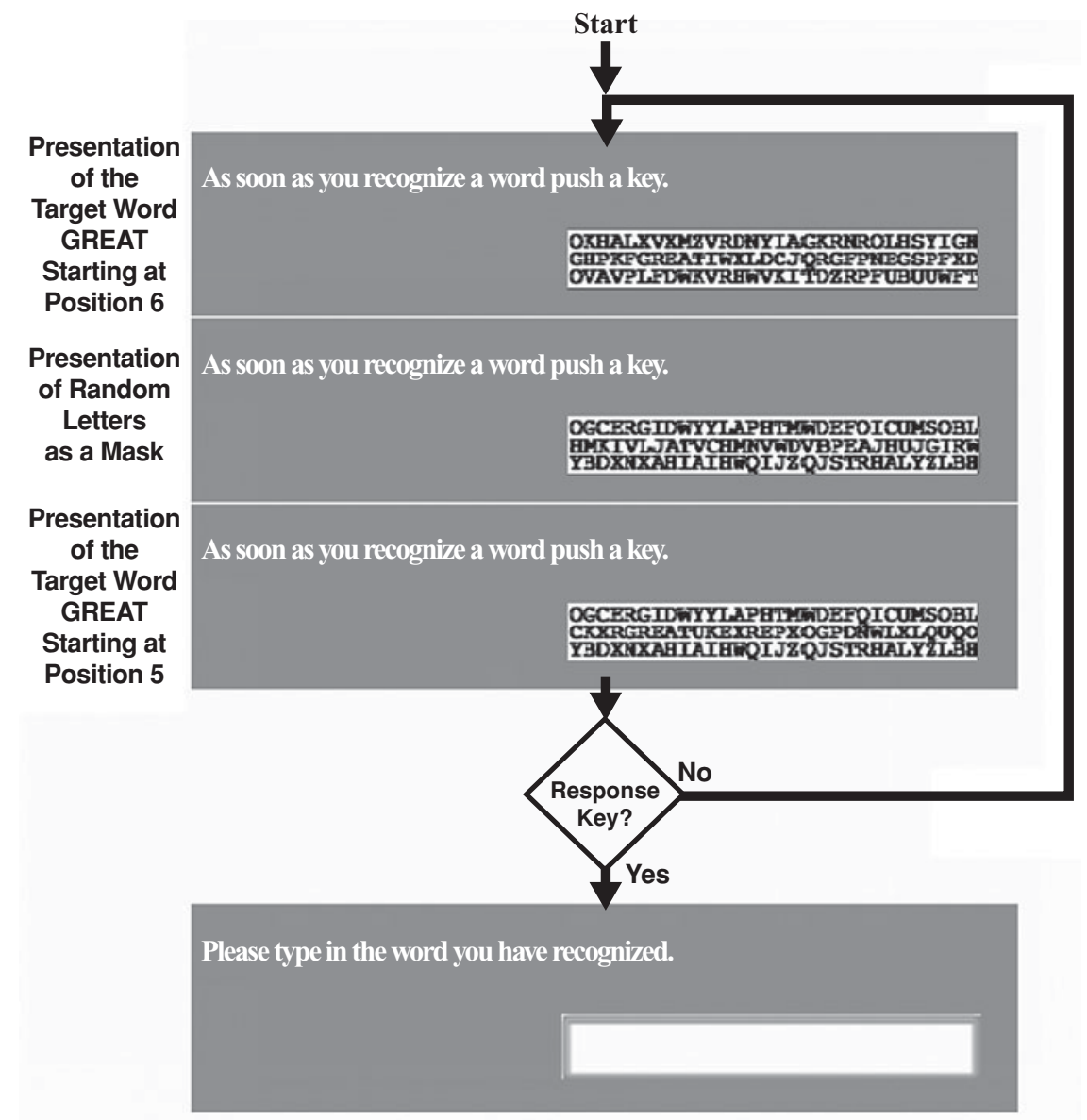

Figure 1. Presentation order of the dynamic display. 
by a presentation of random letters, separated only by a screen refresh. The random letters were drawn from the uppercase letters $A-Z$ of the standard Western alphabet. No constraints were imposed upon the random process: No specific consonant-vowel-consonant constructions were generated, and all letters were equally probable. Because the random letter mask consisted of visual elements equivalent to the ones forming the target, afterimages that participants could read after the actual target presentation were prevented. In order to prevent the target from becoming noticeable because it appeared repeatedly in the same location, successive target presentations had different starting points within the center line (anywhere from the third to the seventh letter position, to allow the entire word to be displayed). The dynamic display cycled between the target word and random letter strings until a response key was pressed. Figure 1 illustrates the presentation procedure.

Such stimulus degradation (or temporal repetition; see Doherty \& Keeley, 1972) can be scaled through shorter or longer target presentation intervals $(200,400$, and $800 \mathrm{msec}$ were used in Experiments 1 and 2). A short target presentation interval of $200 \mathrm{msec}$ should yield percepts of the target word that are not directly readable. Because of the masking and the subsequent display at random positions, there should also be no increasingly clearer percepts over successive repetitions. In terms of Besner and Smith's (1992) model of word recognition, the dynamic display should block any usable subword spelling-sound correspondences. The resulting percepts should remain unclear until input from the semantic system has filled the missing portion of the information in the percept. Therefore, at $200 \mathrm{msec}$, there should be an overadditive joint effect of semantic relatedness and stimulus degradation. At longer presentation intervals, no overadditivity of semantic relatedness and stimulus degradation should occur, because more lexical information is available. Thus, presentation intervals of $400 \mathrm{msec}$ should yield percepts that can be completed by information from lexical memory, and the dynamic display should yield an interaction of word familiarity and stimulus degradation. When presentation intervals are long - that is, $800 \mathrm{msec}$ - neither semantic nor lexical top-down information may be fast enough to outperform building the percept from the bottom up. Therefore, the 800-msec presentation interval should yield no overadditive joint effect of a top-down influence and stimulus degradation.

To summarize, people looked for words under difficult perceptual conditions and were asked to indicate when they recognized a word. Preactivated memory content should lead people to recognize familiar words (Experiment 1) or prototypical words (Experiment 2) more quickly than less familiar or less prototypical words, and there should be an interaction of stimulus degradation with both word familiarity and prototypicality. Most importantly, the new display should magnify to the order of seconds differences that are normally on the order of milliseconds with paradigms such as the lexical decision task or the pronunciation task.

\section{EXPERIMENT 1}

\section{Method}

Overview. Words of intermediate or low familiarity were presented at 200-, 400-, or 800-msec durations before masking and were then repeated until recognition. Word recognition latencies and number of correct detections were assessed. Both should reflect the familiarity effect - that is, better recognition of familiar than of less familiar words. The familiarity effect should also be magnified as viewing conditions become more difficult - in other words, with short presentation intervals and masking in temporal repetition.

Participants. Twenty-nine female and 37 male participants completed the experimental procedure and provided enough data for analyses. Twelve additional participants did the task but provided fewer than eight analyzable trials, mostly because of technical problems with latency measurement. This was a dropout rate of $15 \%$, which was tolerable because repeated measurement designs are relatively immune to the consequences of participant loss, in comparison with between-group designs. In the sample, ages ranged from 18 to 49 years, with a mean of 25.6 years. The participants were recruited via www.genpsy.unizh.ch/Ulf/Lab/webexplist.html, a Web site dedicated to psychological research (Reips, 2001), and psycho .unibw-hamburg.de/experimente/default.html, the home page of the author's institution. Six participants indicated that their first language was Danish, Dutch, Filipino, Finnish, Spanish, or Swedish, but the majority's first language was English $(n=60)$. Thirty-four participants were students, 14 had informatics-related occupations, 9 had diverse occupations (e.g., civil servant, engineer, musician, photographer, waitress, writer), 4 were from the economics sector, 2 came from the education/health sector, 1 was a psychologist, and 2 were either unemployed or made no statement about their occupation.

Apparatus, Materials, and Procedure. A computer program, developed as a Java applet, displayed target words. The familiarity of the target words was varied according to Benjafield and Muckenheim's (1989) word list. According to this list, 9 words were of intermediate familiarity (crumble, dispute, evicted, resolve, sceptic, service, special, vintage, and urgence) and 9 were of very low familiarity (refutal, obviate, cankery, cringle, grudger, knacker, nymphal, patrial, and pendule). Word length was constant at seven letters. A total of 28 target words were presented in random order, the first 10 of which were practice trials.

The visual recognition task started, and the participants saw the three lines of random letters with a target word embedded in the center line. The presentation was tachistoscopic for 200,400 , or $800 \mathrm{msec}$ (depending on the experimental condition), followed by a mask consisting of three lines of random letters without an embedded target word. This mask was displayed for $200 \mathrm{msec}$. Following the masking, the same target word was presented at another position in the center line and was masked again in a new cycle. Each target presentation was repeated until the participant gave an answer. The dependent measures were the latency from stimulus onset to the answer and the number of correct recognitions. The presentation stopped when the participant hit a key. A text field then appeared, and the participant was asked to type the word that had been recognized. The next trial started after the participant hit the return key, but with a minimum delay of $5 \mathrm{sec}$ after the preceding trial. At the end of the procedure, the participants were thanked for their help and debriefed. The debriefing stated the experiment's purpose and hypotheses, as well as a code number. The participants were invited to send back an e-mail quoting the number if they wanted feedback about their performance.

A Java applet performed the presentation of the target words. The applet was embedded in an HTML document retrieved from an HTTP server (see Chu, Palya, \& Walter, 1995) that was hosted on a Sun Ultra workstation. This server also received the results transmitted by the applets from the client systems by means of a CGI script (see Kieley, 1996) programmed in Perl (see Schwartz, 1998). 
Internet technology, however, complicates the measurement of accurate reaction times. An inaccurate-timing filter (Eichstaedt, 2001) was incorporated to minimize technical sources of bias. Further issues of Internet-based experimenting (see Reips, 2002) are multiple submissions of data by the same participant or self-selection within subsamples. In addition to the measures Reips suggests, a complete within-subjects design in the present experiment prevented such Internet-based sources of error from affecting the dependent variables. For example, having selected participants with academic occupations in one word familiarity condition and all others in the second word familiarity condition would seriously have impaired the internal validity of the experiment (see also O'Neil \& Penrod, 2001; O'Neil, Penrod, \& Bornstein, 2003). When all independent variables are varied within subjects this cannot occur, however, making dropout rate a less difficult issue. As of the time of publication of this article, the experiment is accessible online at psycho.unibw -hamburg.de/archiv/FAM/index.html.

\section{Results and Discussion}

Computing the dependent measures. Latencies of correctly detected target words were regularly analyzedthat is, the target word had to be typed correctly, or at least recognizably. For the latter case, a computer program, developed in $\mathrm{C}$, took into account the most common spelling errors. Latencies of detections that did not match the target word were also taken into account. Doing so increased the sensitivity of the measure, allowing the assessment of individual differences in semantic activation, because of both induced states (Eichstaedt, 2002; Eichstaedt \& Silvia, 2003, Experiment 2; Silvia \& Eichstaedt, 2004) and traits (Eichstaedt \& Scheffer, 2005; Eichstaedt \& Silvia, 2003, Experiment 1). Although individual differences were not the key issue here and the following data treatment did not change the results substantially, taking into account latencies of nonmatching detections also increased robustness against repeated participation in the study. Latencies of discrepant detections were used if the detected word was in one of the displayed categoriesthat is, when a familiar word was presented and a different word of the target set was detected-which occurred only two times, or in $0.23 \%$ of the observations. Likewise, when an unfamiliar word was displayed and another unfamiliar word of the target set was detected, the accompanying latency was used. In contrast, when a familiar word was presented but an unfamiliar word of the target set was detected, the accompanying latency was discarded. When an unfamiliar word was displayed but a familiar word of the target set was detected, the accompanying latency was also discarded. If no word at all or a word not belonging to the target set was detected, an error penalty (Greenwald, Nosek, \& Banaji, 2003) of the mean plus three standard deviations was used instead of the latency.

Latencies. A $2 \times 2$ ANOVA with the two within-subjects factors familiarity (intermediate vs. low) and presentation interval $(200,400$, or $800 \mathrm{msec})$ indicated the predicted familiarity $\times$ presentation interaction $[F(1,130)=3.145$, $p=.046]$, as is shown in Table 1 . This looks like evidence that shorter presentation intervals produce greater familiarity effects. However, a planned comparison of the 400- and 800-msec presentation intervals only for unfamiliar words $[F(1,65)=7.696, p=.006]$ indicated that
Table 1

Word Recognition Latencies (in Seconds) and Number of Detections as Functions of Word Familiarity and Presentation Interval in Experiment 1

\begin{tabular}{|c|c|c|c|c|c|c|c|c|}
\hline \multirow{3}{*}{$\begin{array}{c}\text { Presentation } \\
\text { Interval }\end{array}$} & \multicolumn{4}{|c|}{ Latencies } & \multicolumn{4}{|c|}{ Number of Detections } \\
\hline & \multicolumn{2}{|c|}{ Familiar } & \multicolumn{2}{|c|}{ Unfamiliar } & \multicolumn{2}{|c|}{ Familiar } & \multicolumn{2}{|c|}{ Unfamiliar } \\
\hline & $M$ & $S D$ & $M$ & $S D$ & $M$ & $S D$ & $M$ & $S D$ \\
\hline $200 \mathrm{msec}$ & 5.30 & 3.00 & 6.77 & 3.00 & 2.12 & 0.87 & 1.65 & 0.87 \\
\hline $400 \mathrm{msec}$ & 3.70 & 1.86 & 6.30 & 2.85 & 2.61 & 0.55 & 1.82 & 0.94 \\
\hline $800 \mathrm{msec}$ & 3.47 & 2.00 & 5.40 & 2.80 & 2.73 & 0.48 & 2.08 & 0.93 \\
\hline
\end{tabular}

Note $-N=66$. The maximum number of detections in each cell (the four rightmost columns) was 3 for the entire stimulus set of 18 items. Thus, the overall detection rate was $72.3 \%$.

the interaction effect is based on the difference between the 400- and 800-msec presentation interval conditions. The 200-msec presentation interval did not lead to the greatest familiarity effect. Instead, latencies with familiar words were much higher when measured at the 200-msec presentation interval than when measured at either of the slower presentation intervals.

There was a strong main effect of familiarity $[F(1,65)=$ 97.313, $p<.001]$ in which familiar words led to much lower latencies $(M=4.15)$ than did unfamiliar words $(M=6.15)$. Thus, evidence from the lexical decision and pronunciation tasks (Becker, 1979; Connine et al., 1990; Lewellen et al., 1993; Morrison et al., 1992; Scarborough et al., 1977) was replicated with the dynamic display, although latencies were magnified from milliseconds to seconds.

This Internet experiment had a sample much more heterogeneous, in terms of age and occupation, than the standard student samples, and added to the evidence that Internet-based research can replicate effects previously found in the laboratory (see, e.g., Birnbaum, 2001; Klauer, Musch, \& Naumer, 2000; Krantz, Ballard, \& Scher, 1997; Krantz \& Dalal, 2000; McGraw, Tew, \& Williams, 2000; Reips, 2000). There was also a reliable main effect of presentation interval $[F(1,130)=22.325, p<$ $.001]$, which parallels findings on word stimulus degradation via stimulus intensity of the target (Becker \& Killion, 1977), visual noise (Meyer et al., 1975), and $180^{\circ}$ rotation (Massaro et al., 1978). The main effect of presentation interval is evidence that effects based on the exact stimulus duration can be found using the Internet. This corresponds to findings that a Java-implemented stimulus presentation technique is sufficiently reliable to produce valid data, in contrast with less accurate Internet techniques such as animated GIFs, Java script, authorware, and Flash (Schmidt, 2001).

The interaction effect of word familiarity and presentation interval seems to contradict the core finding of no word frequency $\times$ stimulus degradation interaction (Becker $\&$ Killion, 1977; Besner \& Smith, 1992; Borowsky \& Besner, 1991; Stolz \& Neely, 1995). The use of word familiarity instead of word frequency and the unique features of the dynamic display of stimulus presentation might have contributed to the result. At the 200-msec presentation 
interval, the dynamic display might have blocked any usable subword fragments. In contrast, at the 400 -msec presentation interval an overadditive effect of familiarity and stimulus degradation occurred from enough lexical input to contribute subword spelling-to-sound contingencies at a faster or a slower rate, depending on word familiarity. At the 800 -msec presentation interval, word familiarity and presentation interval were merely additive. The General Discussion section describes this result pattern in conjunction with Besner and Smith's model.

Number of detections. The familiarity $\times$ presentation interaction was not significant $[F(1,130)=1.717$, $p=.184]$, although the pattern of results complemented the interaction found in the latencies (see Table 1). Table 1 also reveals a strong main effect of familiarity $[F(1,65)=$ $58.460, p<.001]$ and a reliable main effect of presentation interval $[F(1,130)=15.809, p<.001]$, both complementary to the latency effects. That is, long latencies went along with fewer correct answers.

\section{EXPERIMENT 2}

\section{Method}

Overview. Words of high or low prototypicality for given categories were presented at 200-, 400-, or 800-msec durations. Word recognition latencies and number of detections should reflect the prototypicality effect - that is, better recognition of prototypic words than of less prototypic words. The prototypicality effect should be magnified when the viewing conditions get more difficult - that is, with short presentation intervals in the dynamic display.

Participants. Forty-three female and 32 male participants completed the experimental procedure and provided enough data for analyses. Additionally, 38 participants did the task but provided only one or no analyzable trials (out of three possible trials) in one or more of the repeated measurement conditions because of problems with latency measurement. This was a dropout rate of $33.6 \%$. In the sample, the ages ranged from 18 to 63 years, with a mean of 31.4 years. The participants were recruited via www.language-experiments.org, a Web site in England dedicated to psychological and linguistic research, and psycho.unibw-hamburg.de/experimente/default.html, the home page of the author's institution. Four participants indicated that their first language was French, German $(n=2)$, or Spanish, but the majority's first language was English $(n=71)$. Twenty-four described themselves as students, 14 had diverse occupations (e.g., civil servant, designer, orchard worker, lawyer, clerical), 12 came from the education/health/social work sector, 11 had an informaticsrelated occupation, 5 were from the economics sector, 1 was a psychologist, and 8 were either unemployed or made no statement.
Apparatus, Materials, and Procedure. Prototypicality was varied according to Uyeda and Mandler's (1980) word list. Names of articles of clothing and fruits were chosen as categories. According to the list, 9 words were highly prototypical for articles of clothing (pants, shirt, dress, trousers, blouse, slacks, skirt, coat, and jacket) and 9 had low prototypicality for this category (slip, stockings, tie, belt, nylons, scarf, hat, girdle, and gloves). For the fruits category, 9 words were highly prototypical (orange, apple, pear, banana, peach, strawberry, cherry, grape, and nectarine) and 9 had low prototypicality (lime, mango, raisin, prunes, fig, pomegranate, coconut, avocado, and tomato). Word length varied between 3 and 11 letters. A total of 46 target words were presented in random order, the first 10 of which were practice trials.

The procedure was similar to that of Experiment 1, except that the categories to which the prototypical and less prototypical target words belonged (i.e., articles of clothing and fruits) were announced in the instruction. The experiment can be accessed online at psycho .unibw-hamburg.de/archiv/PRO/index.html.

\section{Results and Discussion}

Latencies. Latencies were computed as in Experiment 1. A $2 \times 2 \times 2$ ANOVA with the three within-subjects factors category (clothing vs. fruits), prototypicality (high vs. low), and presentation interval $(200,400$, or $800 \mathrm{msec})$ showed a very strong main effect of prototypicality $[F(1,74)=$ $246.351, p<.001]$ and a reliable main effect of presentation interval $[F(1,148)=10.293, p<.001]$. The dynamic display revealed an even stronger effect stemming from prototypicality than from familiarity (Experiment 1). Differences in word recognition latencies due to word prototypicality were magnified to the order of seconds. As in Experiment 1, there was a reliable prototypicality $\times$ presentation interaction effect $[F(1,148)=5.431, p=.005]$, which is evidence that the dynamic display magnified the prototypicality effect. A planned comparison showed that a presentation interval of $200 \mathrm{msec}$ led to larger differences between the prototypicality conditions than did a presentation interval of $400 \mathrm{msec}[F(1,74)=15.220, p<$ .001 ], as is shown in Table 2. Results at the 800 -msec presentation interval were quite similar to those at $400 \mathrm{msec}$. Neither the main effect of category nor any interactions with category were significant. Therefore, this factor is omitted in Table 2.

The presentation $\times$ prototypicality interaction effect resembled the often found interaction of semantic relatedness and stimulus degradation (Becker \& Killion, 1977; Besner \& Smith, 1992; Borowsky \& Besner, 1991; Mas-

Table 2

Word Recognition Latencies (in Seconds) and Number of Detections as Functions of Word Prototypicality and Presentation Interval in Experiment 2

\begin{tabular}{|c|c|c|c|c|c|c|c|c|}
\hline \multirow{3}{*}{$\begin{array}{l}\text { Presentation } \\
\text { Interval }\end{array}$} & \multicolumn{4}{|c|}{ Latencies } & \multicolumn{4}{|c|}{ Number of Detections } \\
\hline & \multicolumn{2}{|c|}{ Prototypical } & \multicolumn{2}{|c|}{ Not Prototypical } & \multicolumn{2}{|c|}{ Prototypical } & \multicolumn{2}{|c|}{ Not Prototypical } \\
\hline & $M$ & $\overline{S D}$ & $M$ & $S D$ & $M$ & $S D$ & $M$ & $S D$ \\
\hline $200 \mathrm{msec}$ & 2.21 & 0.93 & 3.23 & 1.16 & 5.69 & 0.54 & 5.28 & 0.85 \\
\hline $400 \mathrm{msec}$ & 2.21 & 0.96 & 2.82 & 1.00 & 5.79 & 0.41 & 5.53 & 0.64 \\
\hline $800 \mathrm{msec}$ & 2.07 & 0.97 & 2.80 & 1.08 & 5.81 & 0.43 & 5.59 & 0.59 \\
\hline
\end{tabular}

Note $-N=75$. The maximum number of detections in each cell (the four rightmost columns) was 6 for the entire stimulus set of 36 items. Thus, the overall detection rate was $93.6 \%$. 
saro et al., 1978; Meyer et al., 1975; Stolz \& Neely, 1995). The joint effect of presentation interval and prototypicality was overadditive only at the $200-\mathrm{msec}$ presentation interval.

Number of detections. A prototypicality $\times$ presentation interaction was not found, but there was a three-way interaction of category, prototypicality, and presentation interval $[F(1,148)=3.437, p=.03]$, indicating that the larger difference between low and high prototypicality for the 200-msec presentation interval was found only with names of fruits as target words. There were main effects of prototypicality $[F(1,74)=27.148, p<.001]$ and presentation interval $[F(1,148)=5.809, p=.004]$, both of which were complementary to the latency effects (see Table 2). No other effects were significant.

\section{GENERAL DISCUSSION}

Factors of semantic relatedness, such as the prototypicality of a word in relation to its category, as well as lexical factors, such as word familiarity, yield only small latency differences (in the range of milliseconds) when investigated with the lexical decision task or the pronunciation task. No matter how reliable such differences are, if they are too small they might be overlooked when assessed using an Internet experiment. They even might be overlooked in the laboratory when the variability of factors extraneous to the recognition part of responding to stimulus words takes effect. For example, variability in motor responses influences latencies but does not reflect any interpretable factor in the recognition process. The procedure of the dynamic display seems to overcome these problems and allows for the application of word recognition latency-based assessment methods of individual differences in the field of social cognition or personality. To demonstrate the dynamic display's potential to find and magnify differences in word recognition, two experiments were conducted on the missing interaction between word familiarity and stimulus degradation and its implications for the additive-factors logic (Sternberg, 1969).

Experiment 1 showed overadditive joint effects of word familiarity and stimulus degradation that fit the results from Norris (1984) and Wilding (1988), who also found such an interaction. The results of Experiment 2 fit very well the findings that latency differences can be greater when target words are degraded (Borowsky \& Besner, 1991; Stolz \& Neely, 1995).

\section{Models of Word Priming and Word Reading}

Seemingly, the interaction of word familiarity and presentation interval contradicts core findings in the literature that have revealed no evidence of an interaction between word frequency and stimulus degradation (Becker \& Killion, 1977; Besner \& Smith, 1992; Borowsky \& Besner, 1991; Stolz \& Neely, 1995). However, in terms of Besner and Smith's model, the kind of stimulus degradation used here is unique with regard to the input restriction to the orthographic input lexicon. The model holds that word frequency affects the pathways between the orthographic input lexicon, semantic memory, and the phonological output lexicon. At a 200-msec presentation interval, the new procedure seemingly blocks any usable subword spellingsound correspondences. Thus, the pathway from subword spelling-sound correspondences to the phonemic buffer, pathway E in Besner and Smith's model, was blocked, and resulting percepts remained unclear until input from the semantic lexicon replaced the missing information in the percept. Therefore, at $200 \mathrm{msec}$ there was an overadditive joint effect of semantic relatedness and stimulus degradation. At longer presentation intervals, no overadditivity occurred, presumably because more lexical information had become available.

Lexical memory contained no suitable information at the 200-msec presentation interval because few subword spelling-to-sound contingencies were derivable from the input. At the 400-msec presentation interval, however, an overadditive effect of familiarity and stimulus degradation was found, because at $400 \mathrm{msec}$ more lexical input was available to pass through pathway E. At the $800-\mathrm{msec}$ presentation interval, presumably, neither semantic nor lexical information was fast enough to outperform building the percept from the bottom up.

Given this interpretation, the data presented here at least do not contradict Besner and Smith's (1992) model, and they may support it. The data do not support Morton's (1969) original logogen model, however, because according to that model the word detectors (logogens) are affected first at any presentation rate. In that case, there should always have been an interaction of word familiarity and stimulus degradation, which was not the case in Experiment 1. Activation verification models (Becker, 1976; Paap, Newsome, McDonald, \& Schvaneveldt, 1982) predict that no interaction of word familiarity and stimulus degradation should occur, which is also not supported by the data found here. Given the flexibility of parallel distributed processing models (PDP; McClelland \& Rumelhart, 1981; Seidenberg \& McClelland, 1989), this model class could be adapted for the data found here. Parallel routes, both bottom-up and top-down, together with further assumptions about the time course with which information travels on these routes, could be part of an explanation within the PDP framework.

\section{Outlook}

The dynamic display might facilitate the detection of hard-to-find effects. Because this display only magnifies the recognition part and not, for instance, the motor part of word recognition latencies, it might be useful in all applications in which the recognition part is the one under investigation. This magnification allows for investigating memory theory as well as for applying the dynamic display to assessments of individual semantic representationsthat is, to diagnostics. Tests based on the dynamic display can tap content categories that are preactivated as a result of (1) prior experience (e.g., experience with a particular computer operating system; Eichstaedt, 2002, Experiment 1), (2) habitual needs or traits (e.g., habitual needs for affiliation, achievement, or power [Eichstaedt 
\& Scheffer, 2005] or habitual self-consciousness [Eichstaedt \& Silvia, 2003, Experiment 1; Silvia et al., 2005, Experiment 1]), or (3) state-like factors (e.g., expectancy to find positive or negative words [Eichstaedt, 2002, Experiment 2] or self-awareness [Eichstaedt \& Silvia, 2003, Experiment 2]). For example, if people have a strong need for achievement (McClelland, Atkinson, Clark, \& Lowell, 1953), they are faster to respond to words such as success, invention, or incentive; if they have a need for affiliation, they are faster on words like friendship, coziness, or membership.

In general, the new procedure can be seen as a way to assess people's sensitivity to target words from activated content categories. If activation is chronic - that is, structurally channeled as a result of individual differencesdiagnostics based on the dynamic display are possible: If the activation is due to a state, indications of that state can be obtained - for instance, through better recognition of words fitting the individual's emotional state or interest. Also, activation due to a state could be the result of learning. Given the magnification effect, the new procedure of the dynamic display might reveal even subtle improvements in learning that might otherwise be overlooked.

\section{REFERENCES}

BECKER, C. A. (1976). Allocation of attention during visual word recognition. Journal of Experimental Psychology: Human Perception \& Performance, 2, 556-566.

Becker, C. A. (1979). Semantic context and word frequency effects in visual word recognition. Journal of Experimental Psychology: Human Perception \& Performance, 5, 252-259.

BECKER, C. A. (1980). Semantic context effects in visual word recognition: An analysis of semantic strategies. Memory \& Cognition, $\mathbf{8}$, 493-512.

BeCKeR, C. A., \& Killion, T. H. (1977). Interaction of visual and cognitive effects in word recognition. Journal of Experimental Psychology: Human Perception \& Performance, 3, 389-401.

Benjafield, J., \& Muckenheim, R. (1989). Dates of entry and measures of imagery, concreteness, goodness, and familiarity for 1,046 words sampled from the Oxford English Dictionary. Behavior Research Methods, Instruments, \& Computers, 21, 31-52.

Besner, D., \& SMith, M. C. (1992). Models of visual word recognition: When obscuring the stimulus yields a clearer view. Journal of Experimental Psychology: Learning, Memory, \& Cognition, 18, 468-482.

BirnBAUM, M. H. (2001). A Web-based program of research on decision making. In U.-D. Reips \& M. Bosnjak (Eds.), Dimensions of Internet science (pp. 23-55). Lengerich, Germany: Pabst.

BorowsKy, R., \& BESNER, D. (1991). Visual word recognition across orthographies: On the interaction between context and degradation. Journal of Experimental Psychology: Learning, Memory, \& Cognition, 17, 272-276.

Borowsky, R., \& BeSner, D. (1993). Visual word recognition: A multistage activation model. Journal of Experimental Psychology: Learning, Memory, \& Cognition, 19, 813-840.

BorowsKy, R., \& BESNER, D. (2000). Lexical access codes in visual word recognition: Are the joint effects of context and stimulus quality diagnostic? Canadian Journal of Experimental Psychology, 54, 196-207.

Chu, J. Y. M., Palya, W. L., \& Walter, D. E. (1995). Creating a hypertext markup language document for an information server. Behavior Research Methods, Instruments, \& Computers, 27, 200-205.

Connine, C. M., Mullennix, J., Shernoff, E., \& Yelen, J. (1990). Word familiarity and frequency in visual and auditory word recognition. Journal of Experimental Psychology: Learning, Memory, \& Cognition, 16, 1084-1096.
Doherty, M. E., \& Keeley, S. M. (1972). On the identification of repeatedly presented brief visual stimuli. Psychological Bulletin, 78, 142-154.

EICHSTAEDT, J. (2001). An inaccurate-timing filter for reaction time measurement by JAVA applets implementing Internet-based experiments. Behavior Research Methods, Instruments, \& Computers, 33, 179-186.

Eichstaedt, J. (2002). Measuring differences in pre-activation on the Internet: The content category superiority effect. Experimental Psychology, 49, 283-291.

EichSTAEDT, J., \& SCHEFFER, D. (2005). Measuring implicit motives on the basis of word recognition latencies. Manuscript submitted for publication.

Eichstaedt, J., \& Silvia, P. J. (2003). Noticing the self: Implicit assessment of self-focused attention using word recognition latencies. Social Cognition, 21, 349-361.

Greenwald, A. G., Nosek, B. A., \& Banaji, M. A. (2003). Understanding and using the implicit association test: 1. An improved scoring algorithm. Journal of Personality \& Social Psychology, 85, 197-216.

KeEfe, D. E., \& NeELy, J. H. (1990). Semantic priming in the pronunciation task: The role of prospective prime-generated expectancies. Memory \& Cognition, 18, 289-298.

KIELEY, J. M. (1996). CGI scripts: Gateways to World-Wide Web power. Behavior Research Methods, Instruments, \& Computers, 28, 165 169.

Klauer, K. C., Musch, J., \& Naumer, B. (2000). On belief bias in syllogistic reasoning. Psychological Review, 107, 852-884.

Krantz, J. H., Ballard, J., \& Scher, J. (1997). Comparing the results of laboratory and World-Wide Web samples on the determinants of female attractiveness. Behavior Research Methods, Instruments, \& Computers, 29, 264-269.

Krantz, J. H., \& Dalal, R. (2000). Validity of Web-based psychological research. In M. H. Birnbaum (Ed.), Psychological experiments on the Internet (pp. 35-60). San Diego: Academic Press.

Lewellen, M. J., Goldinger, S. D., Pisoni, D. B., \& Greene, B. G. (1993). Lexical familiarity and processing efficiency: Individual differences in naming, lexical decision, and semantic categorization. Journal of Experimental Psychology: General, 122, 316-330.

LORCH, R. F., JR., BALOTA, D. A., \& StAmM, E. G. (1986). Locus of inhibition effects in the priming of lexical decisions: Pre- or postlexical access? Memory \& Cognition, 14, 95-103.

MacLeod, C. M., \& KamPE, K. E. (1996). Word frequency effects on recall, recognition, and word fragment completion tests. Journal of Experimental Psychology: Learning, Memory, \& Cognition, 22, 132142.

Massaro, D. W., Jones, R. D., Lipscomb, C., \& Scholz, R. (1978). Role of prior knowledge on naming and lexical decisions with good and poor stimulus information. Journal of Experimental Psychology: Human Learning \& Memory, 4, 498-512.

McClelland, D. C., Atkinson, J. W., Clark, R. A., \& Lowell, E. L. (1953). The achievement motive. New York: Appleton-CenturyCrofts.

McClelland, J. L., \& Rumelhart, D. E. (1981). An interactive activation model of context effects in letter perception: I. An account of basic findings. Psychological Review, 88, 375-407.

McGraw, K. O., Tew, M. D., \& Williams, J. E. (2000). The integrity of Web-delivered experiments: Can we trust the data? Psychological Science, 11, 502-506.

Meyer, D. E., Schvaneveldt, R. W., \& Ruddy, M. G. (1975). Loci of contextual effects on visual word recognition. In P. M. A. Rabbitt \& S. Dornic (Eds.), Attention and performance V (pp. 98-118). New York: Academic Press.

Morrison, C. M., Ellis, A. W., \& Quinlan, P. T. (1992). Age of acquisition, not word frequency, affects object naming, not object recognition. Memory \& Cognition, 20, 705-714.

MorTon, J. (1969). Interaction of information in word recognition. Psychological Review, 76, 165-178.

Neely, J. H. (1991). Semantic priming effects in visual word recognition: A selective review of current findings and theories. In D. Besner \& G. W. Humphreys (Eds.), Basic processes in reading: Visual word recognition (pp. 264-336). Hillsdale, NJ: Erlbaum. 
Neely, J. H., Keefe, D. E., \& Ross, K. L. (1989). Semantic priming in the lexical decision task: Roles of prospective prime-generated expectancies and retrospective semantic matching. Journal of Experimental Psychology: Learning, Memory, \& Cognition, 15, 1003-1019.

Norris, D. (1984). The effects of frequency, repetition and stimulus quality in visual word recognition. Quarterly Journal of Experimental Psychology, 36A, 507-518.

O'NeIL, K. M., \& Penrod, S. D. (2001). Methodological variables in Web-based research that may affect results: Sample type, monetary incentives, and personal information. Behavior Research Methods, Instruments, \& Computers, 33, 226-233.

O'Neil, K. M., Penrod, S. D., \& Bornstein, B. H. (2003). Web-based research: Methodological variables' effects on dropout and sample characteristics. Behavior Research Methods, Instruments, \& Computers, 35, 217-226.

Paap, K. R., Newsome, S. L., McDonald, J. E., \& Schvaneveldt, R. W. (1982). An activation-verification model for letter and word recognition: The word-superiority effect. Psychological Review, 89, 573-594.

ReIPS, U.-D. (2000). The Web experiment method: Advantages, disadvantages, and solutions. In M. H. Birnbaum (Ed.), Psychological experiments on the Internet (pp. 89-114). San Diego: Academic Press.

ReIPS, U.-D. (2001). The Web Experimental Psychology Lab: Five years of data collection on the Internet. Behavior Research Methods, Instruments, \& Computers, 33, 201-211.

REIPS, U.-D. (2002). Standards for Internet-based experimenting. Experimental Psychology, 49, 243-256.

Scarborough, D. L., Cortese, C., \& Scarborough, H. L. (1977). Frequency and repetition effects in lexical memory. Journal of Experimental Psychology: Human Perception \& Performance, 3, 1-17.

SCHMIDT, W. C. (2001). Presentation accuracy of Web animation methods. Behavior Research Methods, Instruments, \& Computers, 33, 187-200.

SChWARTZ, A. (1998). Tutorial: Perl, a psychologically efficient refor- matting language. Behavior Research Methods, Instruments, \& Computers, 30, 605-609.

Seidenberg, M. S., \& McClelland, J. L. (1989). A distributed, developmental model of word recognition and naming. Psychological Review, 96, 523-568.

Silvia, P. J., \& Eichstaedt, J. (2004). A self-novelty manipulation of self-focused attention for Internet and laboratory experiments. Behavior Research Methods, Instruments, \& Computers, 36, 325-330.

Silvia, P. J., EichSTAedt, J., \& PhilliPs, A. G. (2005). Are rumination and reflection types of self-focused attention? Personality \& Individual Differences, 38, 871-881.

STERNBERG, S. (1969). The discovery of processing stages: Extensions of Donders' method. In W. G. Koster (Ed.), Attention and performance II (pp. 276-315). Amsterdam: North-Holland.

Stolz, J. A., \& Neely, J. H. (1995). When target degradation does and does not enhance semantic context effects in word recognition. Journal of Experimental Psychology: Learning, Memory, \& Cognition, 21, 596-611.

Uyeda, K. M., \& Mandler, G. (1980). Prototypicality norms for 28 semantic categories. Behavior Research Methods \& Instrumentation, 12, 587-595.

WiLDING, J. M. (1988). The interaction of word frequency and stimulus quality in the lexical decision task: Now you see it, now you don't. Quarterly Journal of Experimental Psychology, 40A, 757-770.

\section{NOTE}

1. Top-down factors are influences from higher cognitive processes on perceptual processes such as content, preformation, and preactivation in lexical or semantic memory.

(Manuscript received October 30, 2003;

revision accepted for publication December 27, 2004.) 